\title{
ASSESSMENT OF DIFFERENT ORGANIC MATTERS ON ANTIOXIDATIVE ENZYME ACTIVITIES AND NUTRITIONAL COMPONENTS UNDER SALT STRESS IN SALAD ROCKET (ERUCA SATIVA)
}

\author{
S. Kusvuran ${ }^{1 *}$ and S. S. Ellialtioglu ${ }^{2}$ \\ ${ }^{1 *}$ Cankiri Karatekin University, Kizilirmak Vocational High School, Cankiri, Turkey, skusvuran@gmail.com \\ ${ }^{2}$ Ankara University, Faculty of Agriculture, Department of Horticulture, Ankara, Turkey, sebnemellialti@gmail.com \\ *Corresponding author's email: skusvuran@gmail.com
}

\begin{abstract}
Salad rocket (Eruca sativa), which is becoming increasingly important, comprises a wide variety of phytochemicals that promote health, such as carotenoids, fibers, glucosinolates (GLs), polyphenols, and ascorbic acid (AsA). Variations in the nutritional components of a rocket cultivar and the effects of different organic matter on biochemical changes under salt stress were examined herein. The response of salad rocket (Eruca sativa-) to applications of farmyard manure, humic acid, or vermicompost, as well as water irrigation salinity at $8 \mathrm{dS} \mathrm{m}^{-1}$ was evaluated under greenhouse conditions using plastic pots containing $12 \mathrm{~L}$ of loamy sand. For each experiment, 5 treatments were performed, as follows: 1) control [C: $\mathrm{NaCl}$-free], 2) salt treatment [S: irrigation with solution contained $\left.8 \mathrm{dS} \mathrm{m}^{-1}\right]$, 3) salt treatment + cow manure [SM: irrigation with solution contained $8 \mathrm{dS} \mathrm{m}^{-1}+$ farmyard manure $136 \mathrm{~g} \mathrm{pot}^{-1}$ ], 4) salt treatment $+\mathrm{HA}$ [SH: irrigation with solution contained $8 \mathrm{dS} \mathrm{m}^{-1}+100 \mathrm{ppm} \mathrm{HA}$ ], 5) salt treatment + vermicompost (worm casting) [SV: irrigation with solution contained $\left.8 \mathrm{dS} \mathrm{m}^{-1} \mathrm{EC}+13.6 \mathrm{mg} \mathrm{pot}^{-1}\right]$. The experimental treatments were arranged in a randomized plot design with four replicates. At the experiment's conclusion, the malondialdehyde (MDA), total phenolic, flavonoid, AsA, total GLs contents, and antioxidative enzyme activities [ascorbate peroxidase (APX), catalase (CAT), glutathione reductase (GR), and superoxide dismutase (SOD)] were determined in the rocket leaves. The results revealed that the salt stress caused decreased photosynthetic pigments like total chlorophyll (Chl), Chl-a, Chl-b, and carotenoid contents, as well as total the GLs and phenolic contents, while total flavonoid, AsA, and SOD, CAT, APX, and GR activities showed an increase. The organic matter applications provided tolerance at different levels, and following the aforementioned procedures, there were significant increases (19\%-134\%), but the MDA content was reduced by $47 \%$. Moreover, the application of organic matter increased the total GLs and antioxidative enzyme activities of APX, CAT, GR, and SOD under salt stress (21-424\% increase). The results supported the application of organic matter to increase the defense system of rocket plant, enabling it to tolerate the negative effects induced by salinity. In addition, these applications contributed to the antioxidative defense system components in salad rocket.
\end{abstract}

Keywords: Antioxidative enzyme activities, Eruca sativa, humic acid, organic matter, manure, total glucosinolates

Published first online January 21, 2021.

Published Final August 07, 2021.

\section{INTRODUCTION}

Salad rocket (Eruca sativa) is a significant leafy vegetable crop, as well as an excellent antioxidant and anticancer molecule source [like glucosinolates (GLs)], which contains various sulfur compounds. In addition to GLs, rocket also comprises a high amount of fiber, minerals with nutritional importance, and secondary metabolites, such as ascorbic acid (AsA), carotenoids, and flavonoids, all of which are antioxidants. Antioxidant compounds that have been derived from plants have free radical scavenging properties and are produced mainly in leaves and flowers as a response to oxidative stressors and senescence degeneration. Among leafy vegetables in the family Brassicaceae, rocket comprises the highest AsA content, at levels in the leaves of $\sim 110 \mathrm{mg} 100 \mathrm{~g}^{-1}$ (Cavaiuolo et al. 2014). In addition, in a study of clinical reports, Amiripour et al. (2016) attributed anticancer activity, which inhibits tumor production, liver protection, antiulcer, and antiinflammatory activity, to this plant.

GLs, the main nitrogen source promoting health in Brassica, are a group of secondary metabolites that contain nitrogen and sulfur, which have received a lot of attention recently because of the exceptional anticarcinogenic activity of their isothiocyanates, which is a major product of hydrolysis (Yuan et al. 2010). From a human viewpoint, potential plant usefulness, as well as human health, is influenced by glucosinolate metabolites (Villatoro-Pulido et al. 2012).

Salinity is a significant abiotic stress factor that threatens agriculture in both arid and semiarid environments. It affects over $20 \%$ of irrigated land worldwide, and $40 \%$ of the food produced around the world is impacted by increased amounts of salt, as the amount of land affected by salinity is on the rise. Salt 
stress results in changes in the biochemical, physiological, and morphological responses of a plant, leading to reduced growth, yield, biomass, and quality of crop plants. Salinity causes excessive reactive oxygen species (ROS) accumulation, possibly resulting in enzyme inactivation, damage to DNA, lipid peroxidation, protein oxidation, and interaction with other essential plant cell components. Salt stress reduces stomatal conductance, thereby limiting $\mathrm{CO}_{2}$ supply to the leaf. This in turn causes the over-reduction of the photosynthetic electron transport chain, resulting in the production of ROS such as hydroxyl radical $(\mathrm{OH})$, hydrogen peroxide $\left(\mathrm{H}_{2} \mathrm{O}_{2}\right)$, singlet oxygen $\left(\mathrm{O}_{2}\right)$, and superoxide $\left(\mathrm{O}_{2}^{-}\right)$(Parihar et al. 2015). To minimize the toxic effects caused by ROS, plants possess various kinds of enzymatic and nonenzymatic antioxidative systems components. The enzymatic components comprise ascorbate peroxidase (APX), catalase (CAT), superoxide dismutase (SOD), and glutathione reductase (GR), whereas nonenzymatic antioxidants consist of ascorbate, reduced glutathione (GSH), carotenoids, and tocopherol. SOD consists of enzymes that facilitate the conversion of $\mathrm{O}_{2}{ }^{-}$to $\mathrm{H}_{2} \mathrm{O}_{2} \cdot \mathrm{H}_{2} \mathrm{O}_{2}$ is then scavenged further by APX and CAT, leading to $\mathrm{H}_{2} \mathrm{O}$ and $\mathrm{O}_{2}$. After oxidization, reduction of the ascorbate is done by the glutathione (GSH) caused by the oxidized glutathione (GSSG), which is then catalyzed by GR, resulting in the loss of nicotinamide adenine dinucleotide phosphate-oxidase (NADPH) (Kusvuran et al. 2013).

As chemical fertilizers are both expensive and have dangerous effects, the use of organic compound is on the rise. Furthermore, nutrient supply and chemical fertilizer usage restriction in soils under salt stress are considerable issues that must be resolved using appropriate methods and effective management implementation. Organic fertilizers result in improve soil composition and increase availability of nutrients, which aid in protecting quality and yield, and they are less expensive than synthetic ones (Bidabadi et al. 2017). Generally, the biological, chemical, and physical properties of soil are improved following the incorporation of organic manure. Adding organic waste to soil, which reduces evaporation, while moderating the temperature of the soil, reduces stress to the roots of the plant and supplies nutrients, which in turn, results in productivity enhancement (Ahmed et al. 2010). Morever, Leskovar and Othman (2018) reported that organic foods are significantly more nutritious than conventional foods and these had less pesticide residues and antibioticresistant bacteria. Organic manure has been reported to improve fruit and vegetable bioactive compound contents, such as beta-carotene, flavonoids, lycopene, and phenol, as well as antioxidant activity (Aina et al. 2019). The application of manure is well-known for its ability to improve and preserve the biological, chemical, and physical properties of soil, as well as provide various nutrients, such as $\mathrm{N}$. As a soil enhancer and fertilizer, manure is a highly valuable resource (Irshad et al. 2002). Humic acid (HA), a significant constituent in organic fertilizer, is the result of the biological and chemical and breakdown of organic matter. It is one of the main constituents of organic soil material, and it improves crop growth and yield, as well as the chemical and physical characteristics of the soil, like aeration, aggregation, ion availability, and transportation via $\mathrm{pH}$ buffering, permeability, and capacity for holding water (Shaaban et al. 2013). Vermicomposts are formed via the compression of the organic waste of earthworms, and they comprise a form of nutrients that is absorbed easily by plants (Bidabadi et al. 2017). They also comprise regulators for plant growth, such as auxins, cytokinins, and other materials that influence plant growth, like humates, which are produced by microorganisms and positively affect the growth and productivity of various crops. Previous research has reported that vermicompost is able to modulate the dangerous effects of salt stress on various crops (Bidabadi et al. 2017; Jabeen and Ahmad 2017). With rocket, as is with many crops, the availability of water and nutrients, environmental effects, such as salinity, drought, and light, are the most important agronomic factors influencing quality and yield. According to Hamilton and Fonseca (2010), plants grown under conditions of salinity stress have higher leaf phenolic concentrations.

Although some cultural precautions can be applied to combat these issues, these applications are restricted, temporary, and their costs are too high. Therefore, resistant varieties for abiotic stress should be developed over the long-term. In this respect, while the development of varieties that are resistant to abiotic stress factors, such as salinity, is a more permanent measure in the long-term, it is of great importance to search alternative solutions to increase the production amount in the short-term, and to realize these alternatives within the framework of sustainable agriculture. Hence, the following 2 hypotheses were tested: 1) the effects of different organic fertilizers were investigated on salt tolerance in rocket, and 2) how these organic substances induce a change in some biochemical parameters, which are important for human health, such as total flavonoids, phenolic compounds, antioxidative enzyme activity, and total GLs.

\section{MATERIALS AND METHODS}

Growth conditions: A glasshouse experiment was conducted in the Cankiri Karatekin University, Cankiri, Turkey (from April 7th to the end of May 18th 2018) to identify the impact of different organic matter (cow manure, worm casting (vermicompost), or humic acid) and salt-stress on various biochemical and physiological characteristics of rocket. They were carried out in a 
greenhouse environment (natural daylight, relative air humidity of $65 \%$, and day/night air temperature of $21 \pm 2$ / $\left.15 \pm 2{ }^{\circ} \mathrm{C}\right)$. The experimental plants were grown in plastic pots containing $11 \mathrm{~L}(57 \mathrm{~cm}$ width $\times 16 \mathrm{~cm}$ height $\mathrm{x} 12 \mathrm{~m}$ length) of loamy sand ( $\mathrm{pH}$ : 7.9, electrical conductivity (EC): $0.35 \mathrm{dS} \mathrm{m}^{-1}$, available $\mathrm{P}_{2} \mathrm{O}_{5}: 77 \mathrm{mg} \mathrm{kg}^{-1}$, available $\mathrm{K}_{2} \mathrm{O}$ : $1569 \mathrm{mg} \mathrm{kg}^{-1}$, organic matter: $0.35 \%$ ). According to previous studies, the salt concentration was determined as $8 \mathrm{dS} \mathrm{m}^{-1}$ (Ashraf 1994; Miceli et al. 2003; Hamilton and Fonseca 2010; Kusvuran et al. 2018). A salt solution was prepared using sodium chloride $(\mathrm{NaCl})$. Plants in the control group were cultivated and grown under stress-free conditions for the same duration of time. Organic matters (cow manure, vermicompost or humic acid) were mixed into the soil for one time just prior to the rocket being planted. For each experiment, 5 treatments were performed, as follows: 1) control [C: $\mathrm{NaCl}$-free], 2) salt treatment [S: irrigation with solution contained $8 \mathrm{dS} \mathrm{m}^{-1}$ ], 3) salt treatment + cow manure [SM: irrigation with solution contained $8 \mathrm{dS} \mathrm{m}^{-1}+$ cow manure $136 \mathrm{~g} \mathrm{pot}^{-1}$ ], 4) salt treatment + humic acid $[\mathrm{SH}$ : irrigation with solution contained $8 \mathrm{dS} \mathrm{m}^{-1}+100 \mathrm{ppm}$ humic acid], 5) salt treatment + vermicompost (worm casting) [SV: irrigation with solution contained $8 \mathrm{dS} \mathrm{m}^{-1}+13.6 \mathrm{mg} \mathrm{pot}^{-}$ ${ }^{1}$ ]. The cow manure (136 $\left.\mathrm{g} \mathrm{pot}^{-1}\right)$ and vermicompost (13.6 mg pot $^{-1}$ ) were calculated according to 10 - and 2-ton ha1 , respectively. Free drainage was applied under the pots to prevent excessive salt accumulation. The water collected in the pots was measured after each irrigation with the help of EC meters in order to keep the EC dose constant. Calculation of the volume of water used in the experiment was done in accordance with the drained water/applied water ratio (Schröder and Lieth 2002), which was, under the stress-free conditions of the control, around $30 \%$. The experimental treatments were arranged in a randomized plot design with four replicates. The monitored parameters were measured at the end of the experiment.

Malondialdehyde content: The amount of malondialdehyde (MDA) established by the reaction of thiobarbituric acid (TBA) was used to measure the lipid peroxidation (Heath and Packer 1968). A mortar that was pre-chilled was used to homogenize the frozen samples, to which 2 volumes of ice-cold $0.1 \%(\mathrm{w} / \mathrm{v})$ trichloroacetic acid (TCA) was added, followed by centrifugation at $15,000 \times \mathrm{g}$ for $15 \mathrm{~min}$. As an assay, a mixture comprised of a $1-\mathrm{mL}$ aliquot of supernatant and $2 \mathrm{~mL}$ of $0.5 \%(\mathrm{w} / \mathrm{v})$ TBA in $20 \%(\mathrm{w} / \mathrm{v})$ TCA was heated to $95^{\circ} \mathrm{C}$ for $30 \mathrm{~min}$, after which, it was cooled rapidly in an ice bath. Following centrifugation of the supernatant at $10,000 \times g$ at $4{ }^{\circ} \mathrm{C}$ for $10 \mathrm{~min}$, the absorbance was read at $532 \mathrm{~nm}$ and values that corresponded to nonspecific absorption at $600 \mathrm{~nm}$ were subtracted.

Photosynthetic pigments: Determination of the total carotenoid and chlorophyll (Chl) a and b and contents was done according to the method of Arnon (1949). Extraction of the leaf pigment was done using $80 \%(\mathrm{v} / \mathrm{v})$ acetone and the extraction absorbance was measured with a spectrophotometer (Shimadzu UVmini-1240; Shimadzu Corporation, Kyoto, Japan) at 663, 645, and $470 \mathrm{~nm}$.

Total phenolic and total flavonoid contents: A FolinCiocalteu reagent was used for the determination of the total phenolic content. The phenolic content of the leaves was expressed in milligrams. Gallic acid was used as a standard (Singleton et al. 1999). Determination of the flavonoid content was done via a colorimetric assay (Medina-Juárez et al. 2012). Expression of the total flavonoids was done on the basis of fresh weight (fw), as the milligrams of quercetin equivalents/gram.

Ascorbic acid (vitamin C): A high-speed warring blender was used to blend the rocket leaves for $3 \mathrm{~min}$. Of the blended sample, $5 \mathrm{~g}$ was then mixed with $45 \mathrm{~mL}$ $0.4 \%$ oxalic acid, which was then filtered through filter paper. Next, $9 \mathrm{~mL}$ of 2,6-dichlorophenolindophenol sodium salt was mixed with $1 \mathrm{~mL}$ of the filtrate and a UV spectrophotometer was used to measure the transmittance value at $520 \mathrm{~nm}$. The same method was followed for the preparation of the blank, except that the $1 \mathrm{~mL}$ of filtrate was mixed with $9 \mathrm{~mL}$ of distilled water. The results were expressed as mg $100 \mathrm{~g}^{-1}$ (Ozdemir and Dundar 2006).

Total glucosinolates (GLs): The total GLs were determined according to the method of Gallaher et al. (2012). After being shock frozen in liquid nitrogen, treatment of the ground and lyophilized vegetables was done using $80 \%$ boiling methanol for the deactivation of the extract GLs. Next, the GLs were flushed out via a strong anion exchange extraction cartridge and treated with $2 \mathrm{~N} \mathrm{NaOH}$ to release the 1-thioglucose. After adding ferricyanide, measurement of the absorption was done at $420 \mathrm{~nm}$ and adjustment of the final values took place for any interfering compounds. The sinigrin internal standard was recovered at $80 \%$.

Antioxidative enzyme activities: A mortar and pestle were used to extract the enzymes of $0.5 \mathrm{~g}$ of leaf tissue, in addition to $5 \mathrm{~mL}$ of extraction buffer that contained 50

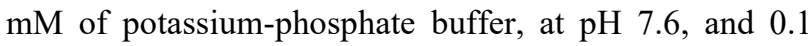
$\mathrm{mM}$ of disodium ethylenediaminetetraacetate. Centrifugation of the homogenate took place for $15 \mathrm{~min}$ at $15,000 \times \mathrm{g}$, and the supernatant fraction from that was used to perform the enzyme assay. All of the enzyme extraction operation preparations were done at $4{ }^{\circ} \mathrm{C}$. The SOD assay was performed according to the method of Karanlik (2001), via monitoring the reduction of the superoxide radical $\left(\mathrm{O}_{2}^{-}\right)$-induced nitro blue tetrazolium (NBT) at $560 \mathrm{~nm}$. Monitoring the disappearance of hydrogen oxide (HO) was used for the determination of the CAT activity. The APX activity was determined via measurement of the ascorbate consumption from its absorbance at $290 \mathrm{~nm}$. One unit of APX activity was 
determined to be the amount of enzyme necessary for the consumption of $1 \mu \mathrm{mol}$ of ascorbate $\min ^{-1}$ (Cakmak and Marschner 1992). Measurement of the enzyme-dependent oxidation of NADPH from its absorbance at $340 \mathrm{~nm}$ was used to determine the GR activity. The amount of enzyme that oxidized $1 \mu \mathrm{mol}$ of NADPH $\mathrm{min}^{-1}$ was defined as 1 unit of GR activity.

The completely randomized plot design was the layout for the current work. Data were statistically analyzed using ANOVA followed by Tukey's HSD test (SPSS 13.0; SPSS Chicago, IL, USA). Significant differences were analyzed based on $P<0.05$ between four means of five treatments. Data are shown as the mean \pm standard deviation (Sd) and in all figures error bars are representing standard errors of the means.

\section{RESULTS AND DISCUSSION}

MDA Content: Often, MDA is used as an indicator for the assessment of damage resulting from abiotic stress. When compared to the control group, the MDA levels were observed to have increased in rocket $(2.30-8.95$ $\left.\mu \mathrm{mol} \mathrm{g} \mathrm{g}^{-1} \mathrm{FW}\right)$. The highest MDA levels were determined in the S treatment group (289\% increases). However, this increase was lower with the treatment of organic fertilizer in plants grown under salt stress (Fig. 1.). In point of fact, through treatment with organic matters, the MDA content was decreased by $53 \%-170 \%$. Compared with the salt application, the most obvious reduction in the MDA content was determined as $60 \%$ in the SM treatment group. The overall increase trend was visualized as: SV> SH $>$ SM. Salt stress results in the formation of free radicals in plants, which cause irreversible lipid and protein damage. Cell membrane integrity is destroyed by lipid peroxidation, eventually leading to cellular death (Dolatabadian et al., 2008). The lipid peroxidation increase is due to compounds like $\mathrm{OH}, \mathrm{H}_{2} \mathrm{O}_{2}$, and $\mathrm{O}_{2}{ }^{-}$in chloroplasts. MDA, which plays the role of a cellular toxicity bioindicator, is a well-known oxidation that emerges from lipid peroxidation during oxidative stress (Singh et al. 2018). In rice plants exposed to water loss, a HA application was observed to have protected the permeability of the cell membrane (García et al. 2012). In this study, the lipid peroxidation of rocket increased with salt stress. At the same time, the MDA contents of the organic matter, especially in the SM treatment group, were lower than the contents of seedlings in the $\mathrm{C}$ group and $\mathrm{S}$ treatment group. It was clear that organic matter resulted in the improvement of growth quality, as the seedlings that had been exposed to salt stress exhibited less defoliation and necrosis after treatment with organic matter. The results showed that the manure, HA, and vermicompost treatments reduced the MDA levels, presenting a favorable effect in reducing the oxidative stress that emerged from salt stress.

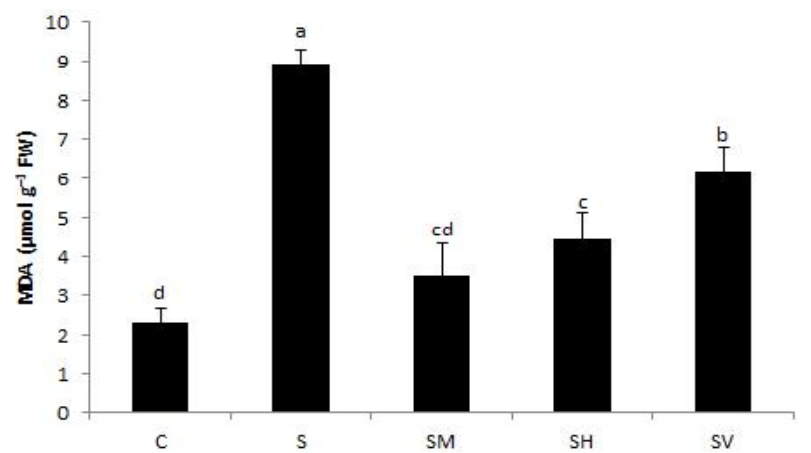

Fig. 1. Effects of different organic matters application on MDA content of rocket plants under salt stress (Means with different superscripts in a column are significantly different $(P<0.05)$ according to Tukey test. Data are shown as the mean \pm standard deviation (Sd) and in all figures error bars are representing standard errors of the means.)

Photosynthetic pigments: Under salt stress $\left(8 \mathrm{dS} \mathrm{m}^{-1}\right)$, photosynthetic pigments like total Chl, Chl-a, Chl-b, and the total carotenoids were reduced by $64 \%, 55 \%, 76 \%$, and $57 \%$, respectively (Fig 2). Applying organic matter mitigated the reduction of photosynthetic pigments under salt stress (decreases of $20 \%-23 \%, 18 \%-35 \%, 3 \%-21 \%$ and, $6 \%-38 \%$ ). However, in the SM treatment group, photosynthetic pigments (excluding the total carotenoids) increased by $2 \%-5 \%$ when compared to the $\mathrm{C}$ group. The auxiliary addition of organic matter on the salt-stressed rocket plants induced a significant increase in photosynthetic pigments by $45 \%-136 \%, 286 \%-307 \%$, and $119 \%-189 \%$, in the SM, SH, and SV treatment groups, respectively, when compared to the $\mathrm{S}$ treatment group. Growth inhibition in plants is the result of decreased chlorophyll content, possibly due to the ROSinduced chlorosis, photo-reduction, and triplet chlorophyll formation, which causes serious damage to photosystems I and II, and the formation of chlorophyll in plants (Singh et al. 2018). Even though the application of $\mathrm{NaCl}$ decreased the photosynthetic pigment contents of the seedlings, the application of manure, HA, and, vermicompost limited those decreases. In this study, the favorable effects of the manure treatment were identified through the chlorophyll components, which increased by $136 \%-307 \%$ in the SM treatment group when compared to the $\mathrm{S}$ treatment group. Manure increased the photosynthesis efficiency of saline treatments when compared to those that were untreated and counterparts for rocket. Moreover, these increases were observed in SH and SV treatment groups, in which the photosynthetic pigments increased by $45 \%-286 \%$. Carotenoids essentially play a critical part in light harvesting and oxidative damage protection through the deactivation of singlet oxygen, satisfying the excited triplet state in chlorophyll, and the enhancement of carotenoid synthesis 
as a way of protecting itself from photo-damage caused by the cell division arrest when exposed to salt stress (Singh et al. 2018). According to our results organic matter treatment may have contributed to the further synthesis of carotenoids in stressed salad rocket plants. Carotenoids play a significant role in the photosynthesis process, including light harvesting, photoprotection, scavenging of ${ }^{1} \mathrm{O}_{2}$, the dissipation of excessive energy, and stabilization of the structure (Markou and Nerantzis 2013). Dineshkumar et al. (2020) reported that the increased chlorophyll accumulation in organic fertilizers, even at a decreased rate, could be the result of the cooperative effects of consortium, which facilitates plant $\mathrm{N}$, $\mathrm{P}$, and $\mathrm{K}$ uptake better, resulting in increased chlorophyll accumulation. The application of manure increases soil fertility. Macro and micro nutrients become more available, and the soil microorganism population becomes more abundance (Sutrisno and Yusnawan 2018). Darini (2017) reported that an organic fertilizer can increase the pigment of chlorophyll concentration in Aloe vera. HA may cause an enhancement in the synthesis of the chlorophyll and/or delay chlorophyll degradation in plants (Nardi et al. 2002). In addition, vermicompost may play an important role in the alleviation of the damage induced by salt to chloroplasts via the reduction of chlorophyllase activity. Hosseinzadeh et al. (2018) reported that applying vermicompost fertilizer improved physiological and photosynthetic responses under conditions of moderate stress and nonstress; however, no positive effect was observed under severe water stress. Obtained results showed that organic matter application may have an important role in alleviating the salinity-induced damage to the chloroplasts by reducing chlorophyllase activity.

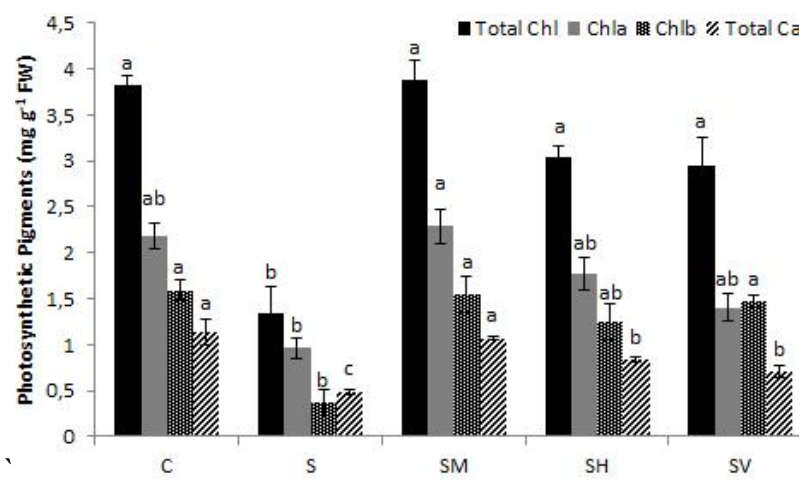

Fig. 2. Effects of different organic matters application on photosynthetic pigments content of rocket plants under salt stress (Means with different superscripts in a column are significantly different $(P<0.05)$ according to Tukey test. Data are shown as the mean \pm standard deviation (Sd) and in all figures error bars are representing standard errors of the means.)
Total phenolic and flavonoid contents: In the $S$ treatment group, the total phenolic contents decreased by $16 \%$, while the flavonoid contents increased by $10 \%$ when compared to the $\mathrm{C}$ group (Fig 3).
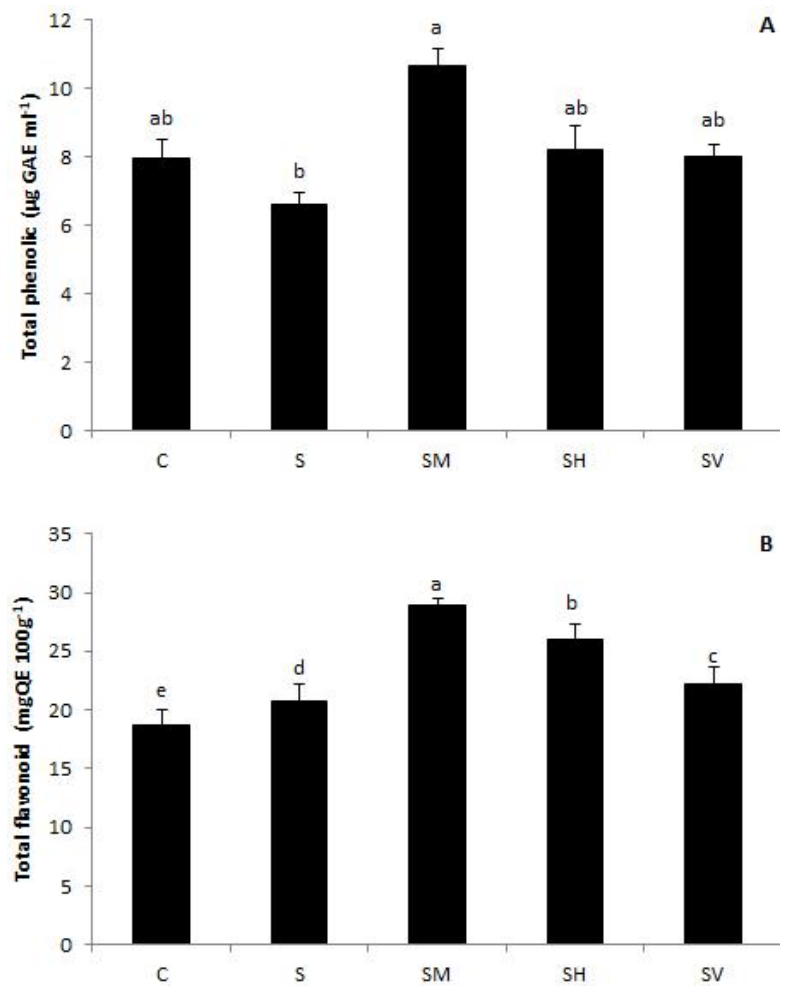

Fig. 3. Effects of different organic matters application on total phenolic (A) and total flavonoid (B) content of rocket plants under salt stress (Means with different superscripts in a column are significantly different $(P<0.05)$ according to Tukey test. Data are shown as the mean \pm standard deviation (Sd) and in all figures error bars are representing standard errors of the means.)

Contrarily, organic fertilizer treatments resulted in a significant increase in the mean values of the total phenolic and flavonoid contents when compared to both the $\mathrm{C}$ group and $\mathrm{S}$ treatment group $(1 \%-24 \%$ and $18 \%$ $54 \%$ ) individually. The maximum mean total phenolics and flavonoid values were obtained in the SM treatment group as $10.64 \mu \mathrm{g} \mathrm{GAE} / \mathrm{mL}$ and $28.86 \mathrm{mg} \mathrm{QE} / 100 \mathrm{~g}$, respectively, which was an increase of $24 \%-54 \%$ when compared to the $\mathrm{S}$ treatment group. On the other hand, when compared to only the $\mathrm{S}$ treatment group, the application of organic matter improved the secondary metabolites average by $23 \%-39 \%$. During extreme environmental conditions, organic matter multiply due to stress and a variety of secondary metabolites that are synthesized and produced, which is assumed to be an endeavor by microorganisms at retaining their rate of 
growth or increasing their likelihood of survival (Markou and Nerantzis 2013). It was concluded previously that a stimulatory effect was produced by organic manures on bioactive compound accumulation via the induction of an acetate shikimate pathway during biosynthesis, which resulted in increased secondary metabolite production, such as phenolics and flavonoids (Aina et al. 2019). In our study, organic matter treatment improved total phenolic and flavonoid in treated plants compared to untreated plants under salt stress condition. These results clearly indicated that the manure, HA, and vermicompost played a stimulatory role in flavonoid and phenolic accumulation in rocket (Fig.3) Organic manure incorporation into soil results in favorable effects on salt stress via the improvement of secondary metabolites. Similarly, in tomato, soil amended with organic cow dung resulted in an increased stimulatory effect on bioactive compounds such as lycopene, phenolics, and flavonoids, as well as antioxidant activity (Aina et al. 2019). The elevated total phenol level is believed to be a result of significant photosynthesis rates, which is predicated by a large photosynthetic area and high photosynthetic pigment levels, using a treatment of yeast as a bio fertilizer. Manure application supplies organic materials that enrich the soil microbe population, such as bacteria, fungi, and nematodes, which then interact with plant roots (Quin et al. 2015). Interaction between the soil microbes and plant roots increases the synthesis of flavonoids. HA has an effect on the regulation of plant hormones and root growth pathways. The effects that HA has on secondary metabolism was recently reported, in addition to the protective effects it has on salt-stressed plants (García et al. 2014).

Ascorbic acid (vitamin C): The amount of AsA was greater $\left(62.42 \mathrm{mg} 100 \mathrm{~g}^{-1}\right)$ in plants that had been exposed to salt stress when compared to those in the control group (Fig. 4). The AsA level in the SM treatment group was $86.97 \mathrm{mg} 100 \mathrm{~g}^{-1}$ and when compared with the $\mathrm{C}$ group, it corresponded to a $56 \%$ increase. Moreover, the application of HA and vermicompost reduced the effects of stress on the AsA and considerably increased it by $29 \%$ in the $\mathrm{SH}$ treatment group and $14 \%$ in the SV treatment group when compared to the $\mathrm{C}$ group. The antioxidant AsA has the ability to non-enzymatically scavenge $\mathrm{O}_{2}^{-}$and $\mathrm{H}_{2} \mathrm{O}_{2}$. It plays a role in the mediated scavenging, by ascorbate peroxidase, of $\mathrm{H}_{2} \mathrm{O}_{2}$. Moreover, it also has some involvement in the regeneration of $\alpha$ tocopherol, which is another significant non-enzymatic antioxidant (Sairam et al. 2005). Koh et al. (2012), in their study of organically-grown spinach (Spinacia oleracea) products reported higher AsA levels and phenolic compounds with less nitrates than conventionalgrown products. Similarly, in medicinal herbs, the application of organic fertilizers increased the total phenolic, flavonoid, and AsA contents (Ibrahim et al.
2013). Ascorbate/vitamin C is a micronutrient that is essential for humans and is obtained predominantly from plants. Moreover, it is a significant plant antioxidant that supports many responses to environmentally-induced abiotic stressors (Macknight et al. 2017). In this study, ascorbic acid contents of rocket plants increased by salt stress (Fig. 4). However, the treatment of rocket plants with organic matter (especially manure) caused considerable increases in these contents as compared with control and salt stress conditions. These increases may be due to the active role of organic matter in the enhancement of antioxidants which scavenging ROS that associated with oxidative stress. As an antioxidant, AsA provides plant cell protection. It was reported that AsA is a substantial plant component. It has involvement with chloroplasts and cell compartments, which includes cell walls and the division of cells, in addition to differentiation. It has been suggested that AsA has a role in photosynthesis, where it behaves as an enzyme cofactor (Nasiri 2016).

Total glucosinolates (GLs): Rocket seedlings in the $\mathrm{S}$ treatment group demonstrated a decrease in the total GLs,

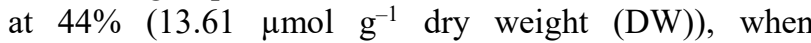
compared to the $\mathrm{C}$ group (Fig. 4). However, a significant improvement in the total GLs in the SM treatment group was observed at an increase of 7\% (26.35 $\left.\mu \mathrm{mol} \mathrm{g}{ }^{-1} \mathrm{DW}\right)$. In the $\mathrm{SH}$ and $\mathrm{SV}$ treatment groups, the total GL content was determined at $19.38 \mu \mathrm{mol} \mathrm{g}^{-1} \mathrm{DW}$ (20\% decrease) and $16.53 \mu \mathrm{mol} \mathrm{g}^{-1} \mathrm{DW}$ (32\% decrease). Compared to the $\mathrm{S}$ treatment group, the organic matter applications enhanced the total GL contents, which were observed as $21 \%-93 \%$. In nature, GLs play a major role in plant defense against abiotic or biotic stresses. GLs are secondary metabolites that are normally associated with properties that promote health (Dinkova-Kostova et al. 2012; Sarıkamış and Çakır 2017). In a study by Pang et al. (2012), GLs were reported to have been influenced by salt stress, which suggests that they may have involvement in osmotic adjustments, with low water potential, and could have involvement in plant salt tolerance (Sarıkamış and Çakır 2017). They also reported that treatment with $\mathrm{NaCl}$ resulted in significant variations in the aromatic, indole, and aliphatic GL concentration patterns, which resulted in differing total GLs levels in various organs at 3 different stages of development. Increased GL degradation is the result of damage to membranes caused by salt stress and is indicated by increased relative electrolyte leakage (Chen et al. 2019). In this study, although total GLs decreased by salt stress, with organic matter application this reduction was limited and improved total GLs level. According to these results, organic matter might have helped osmotic adjustment, and therefore, the increase in the GL content could have been due to limited cellular damage by organic matter against oxidative stress. 

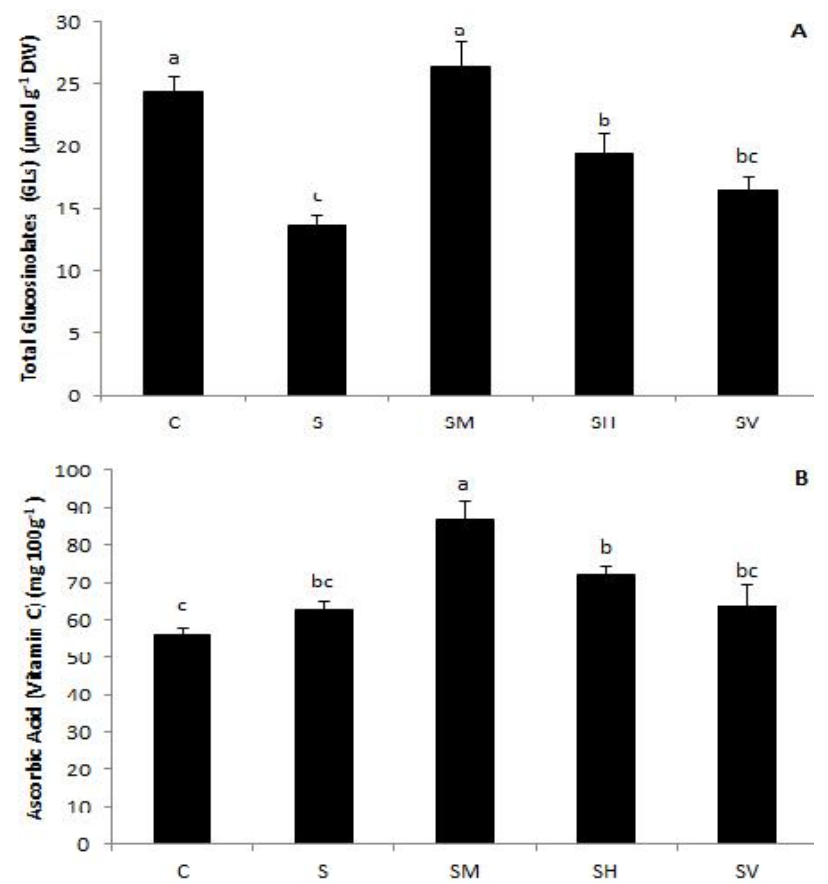

Fig. 4. Effects of different organic matters application on total glucosinolates (A) and total ascorbic acid (Vitamin C) (B) content of rocket plants under salt stress (Means with different superscripts in a column are significantly different $(P<0.05)$ according to Tukey test. Data are shown as the mean \pm standard deviation (Sd) and in all figures error bars are representing standard errors of the means.)

Antioxidative enzyme activities: Under salt stress, the SOD, CAT, APX, and GPX activities were upregulated and increased significantly by $54.2 \%, 58.5 \%, 48.1 \%$, and $37.6 \%$, respectively, in the S, SM, SH, and SV treatment groups when compared to the control group (Fig. 5). However, organic fertilizer increased the SOD, CAT, APX, and GPX activities further when compared to the S treatment and $\mathrm{C}$ group. The application of manure led to a greater effect, resulting in increases in the antioxidant enzyme activity by $222 \%, 424 \%, 413 \%$, and $144 \%$, respectively, in the $\mathrm{S}, \mathrm{SM}, \mathrm{SH}$, and $\mathrm{SV}$ treatment groups. ROS in plant cells are generated via normal cellular metabolism or stressful environmental conditions, such as drought, heavy metals, herbicides, nutrient deficiency, radiation, or salinity. A direct consequence of salinity is the induction of stress and antioxidant enzymes by exposed plants to minimize the damage caused by ROS (Amar and Nourredine 2016). Enzymatic antioxidant defense systems include APX, CAT, DHAR, GR, MDHAR, POX, and SOD; and non-enzymatic antioxidant defense systems include ascorbate, carotenoids, glutathione, glycine betaine, phenolic compounds, polyamines, proline, and sugar (Sen 2012). Photosynthetic photosystems I (PSI) and PSII reaction centers are the central chloroplast ROS production locations under light conditions. $\mathrm{O}_{2}^{-}$is the result of the Mehler reaction in the PSI systems in the antenna pigments. Next, it is converted by SOD to $\mathrm{H}_{2} \mathrm{O}_{2}$, which acts as the main ROS scavenger and is the most efficient metalloenzyme. It is then reduced even further by APX in the water-water cycle (Bose et al., 2014). $\mathrm{H}_{2} \mathrm{O}_{2}$ is significantly scavenged by catalase into $\mathrm{H}_{2} \mathrm{O}$ and $\mathrm{O}_{2}$ in the peroxisome. Under stress, GR sustains the cytoplasm's GSSG-to-GSH pool, preserving the balance of redox in the cells through the inter-conversion of the reduced GSH and oxidized GSSG that was catalyzed by the GR. Herein, responses to organic matter applications in the salt-stressed medium were examined and an increase in antioxidative enzyme activity like APX, SOD, GR, and CAT was reported. These increases were statistically significant and determined as $80 \%-424 \%$. Enhancement of antioxidative enzyme activities in organic matter treated plants may be induced by the salt resistance of rocket plants. Application of organic matter can be used as a growth regulator which improves plant growth and enhanced stress tolerance. These may increase the uptake of ions such as potassium and calcium in the plant. Therefore, calcium acts as an activator for the enzyme and potassium inhibits plant damage by reducing transpiration. According to García et al. (2016), the present understanding of the biochemical and molecular mechanisms that are involved in the favorable effects of dissolved organic matter, like vermicompost and humic substances on the development of plants is incomplete. Such mechanisms might include coordinated signaling pathway actions, which are controlled by crucial plant regulators like auxin, ethylene, nitric oxide, and cytokinins, as well as secondary messengers, like and $\mathrm{Ca}^{2+}$ and ROS. Aina et al. (2019) indicated that organic manure, instead of inorganic fertilizer, was also reported to have increased secondary metabolite levels, such as phenolic, flavonoids, and plant antioxidant activity. Researchers have also reported that organically grown vegetables have reactions to conditions like stress via the activation of their own mechanisms for defense, which results in increased antioxidant and bioactive compound synthesization. The signaling pathways for detoxifying ROS are activated via the synthesization of ROS-scavenging antioxidants. Similarly, Hosseinzadeh et al. (2018) indicated that organic matter leads to increased nutrient absorption, total enzymatic activity, capacity of cation exchange, and water holding. 

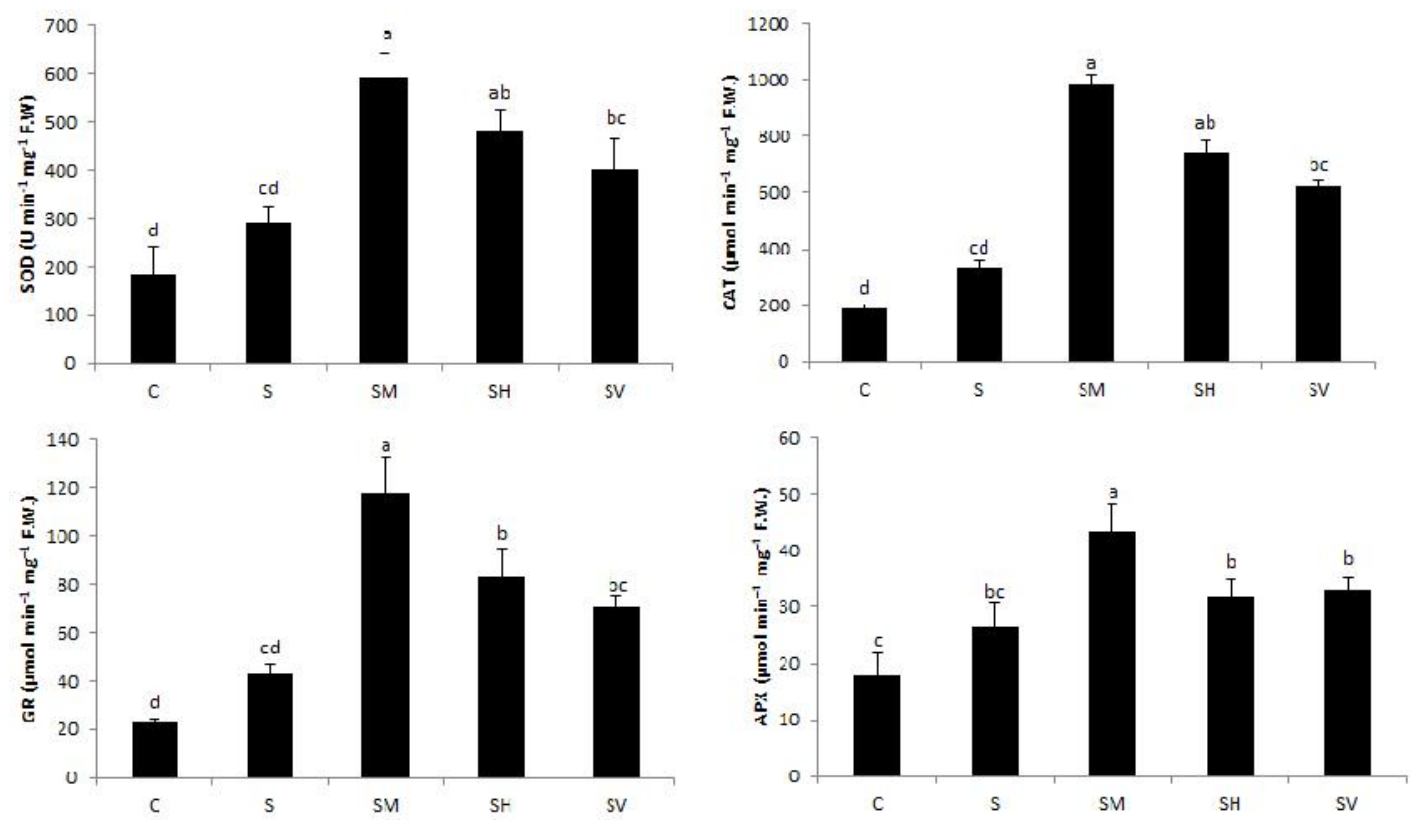

Fig. 5. Effects of different organic matters application on antioxidative enzyme activities (SOD, CAT, GR, and APX) of rocket plants under salt stress (Means with different superscripts in a column are significantly different $(P<0.05)$ according to Tukey test. Data are shown as the mean \pm standard deviation (Sd) and in all figures error bars are representing standard errors of the means.)

Conclusion: Organic fertilizers are important for the environment, and are a favorable and renewable cheaper source for agricultural practices. The application of organic matter under salt stress appeared to be favorable for the physiological and biochemical processes of the rocket salads. From the results presented herein, a conclusion can be made that the application of organic fertilizer could effectively increase the photosynthetic pigments, total flavonoid contents, and AsA, in addition to reducing in the MDA of rocket plants, under salt stress. Moreover, the application of organic matter increased the total GLs and antioxidative enzyme activities of APX, CAT, GR, and SOD under salt stress. Interestingly, in the current study, even though all of the organic matter components improved salt tolerance, the manure was more prominent than the others under salt stress. Hence, we therefore recommend the use of organic fertilizers, which can efficiently improve metabolic and physiological processes, which, in turn, might result in improved salt stress tolerance in rocket plants.

\section{REFERENCES}

Ahmed, B. O., M. Inoue, and S. Moritani (2010). Effect of saline water irrigation and manure application on the available water content, soil salinity, and growth of wheat. Agricultural Water Man. 97: 165-170.

Aina, O. E., S. O. Amoo, L. L. Mugivhisa, and J. O. Olowoyo (2019). Effect of organic and inorganic sources of nutrients on the bioactive compounds and antioxidant activity of tomato. Applied Ecology and Environmental Res. 17: 3681-3694.

Amar, T. and Y. Nourredin (2016). Morphometric variability and biochemical analysis of growth seedlings under salt stress in tomato (Lycopersicon esculentum Mill.) cultivars. Molecular Plant Breed. 7:1-9.

Amiripour, H., B. D. Hashemloian, and A. A. Azimi (2016). Morpho-physiological responses of rocket (Eruca sativa L.) varieties to sodium sulfate $\left(\mathrm{Na}_{2} \mathrm{SO}_{4}\right)$ stress: An experimental approach. Acta Physiol. Plant. 38: 246.

Arnon, D.I. (1949). Copper enzymes in isolated chloroplast: polyphenoloxidase in Beta vulgaris. Plant Physiol. 14: 1-15.

Ashraf, M. (1994). Organic substances responsible for salt tolerance in Eruca sativa. Biologia Plant. 36(2): 255-259.

Bidabadi, S. S., S. Dehghanipoodeh, and G. C. Wright (2017). Vermicompost leachate reduces some negative effects of salt stress in pomegranate. International J. Recycling of Organic Waste in Agri. 6: 255-263.

Bose, J., A. Rodrigo-Moreno, and S. Shabala (2014). ROS homeostasis in halophytes in the context of salinity stress tolerance. J. of Exp. Bot. 65: 1241-1257.

Cakmak, I. and H. Marschner (1992). Magnesium deficiency and highlight intensity enhance 
activities of superoxide dismutase, ascorbate peroxidase and glutathione reductase in bean leaves. Plant Physiol. 98: 1222-1226.

Cavaiuolo, M. and A. Ferrante (2014). Nitrates and glucosinolates as strong determinants of the nutritional quality in rocket leafy salads. Nutrients. 6: 1519-1538.

Chen, W., E. Karangwa, J. Yu, S. Xia, B. Feng, and X. Zhang (2019). Effect of sodium chloride concentration on off-flavor removal correlated to glucosinolate degradation and red radish anthocyanin stability. J. Food Science and Tech. 56: 937-950.

Darini, M. T. (2017). Studies of chemical sandy soil and physiological properties of Aloe vera L. plant on nutrient stress condition. Int. J. of Current Res. 7: 208-212.

Dineshkumar, R., J. Subramanian, A. Arumugam, A. A. Rasheeq, and P. Sampathkumar (2020). Exploring the microalgae biofertilizer effect on onion cultivation by field experiment. Waste and Biomass Valor. 1-11.

Dinkova-Kostova, A. T. and R. V. Kostov (2012). Glucosinolates and isothiocyanates in health and disease. Trends in Molecular Medicine. 18: 337-347.

Dolatabadian, A., S. A. M. M. Sanavy, and N. A. Chashm1 (2008). The effects of application of ascorbic acid (Vitamin C) on antioxidant enzymes activities, lipid peroxidant and proline accumulation of canola (Brassica napus L.) under conditions of salt stress. J. Agronomy and Crop Sci. 194: 206-213.

Gallaher, C. M., D. D. Gallaher, and S. Peterson (2012). Development and validation of a spectrophotometric method for quantification of total glucosinolates in cruciferous vegetables. J. Agricultural and Food Chem. 60: 1358-1362.

García, A. C., R. L. L. Berbara, L. P. Farías, F. G. Izquierdo, O. L. Hernández, R. H. Campos, and R. N. Castro (2012). Humic acids of vermicompost as an ecological pathway to increase resistance of rice seedlings to water stress. African Journal of Biotech. 11: 31253134.

García, A. C., L. A. Santos, F. G. Izquierdo, V. M. Rumjanek, R. N. Casto, F. S. Santos, L. G. A. Souza, and R. L. L. Berbara (2014). Potentialities of vermicompost humic acids to alleviate water stress in rice plants (Oryza sativa L.). Journal of Geochemical Exp. 136: 48-54.

García, A. C., L. A. Santos, L. G. A. de Souza, O. C. H. Tavares, E. Zonta, E. T. M. Gomes, J. M. GarciMina, and R. L. L. Berbera (2016). Vermicompost humic acids modulate the accumulation and metabolism of ROS in rice plants. Journal of Plant Physiol. 192: 56-63.

Hamilton, J. M. and J. M. Fonseca (2010). Effect of saline irrigation water on antioxidants in three hydroponically grown leafy vegetables: Diplotaxis tenuifolia, Eruca sativa, and Lepidium sativum. HortScience. 45: 546-552.

Heath, R. L. and L. Packer (1968). Photoperoxidation in isolated chloroplasts. I. Kinetics and stoichiometry of fatty acid peroxidation. Archives Biochem. and Biophysics 125:189198.

Hosseinzadeh, S. R., H. Amiri, and A. Ismaili (2018). Evaluation of photosynthesis, physiological, and biochemical responses of chickpea (Cicer arietinum L. cv. Pirouz) under water deficit stress and use of vermicompost fertilizer. Journal of Integrative Agri. 17: 2426-2437.

Ibrahim, M., H. Jaafar, E. Karimi, and A. Ghasemzadeh (2013). A, Impact of organic and inorganic fertilizers application on the phytochemical and antioxidant activity of Kacip Fatimah (Labisia pumila Benth). Molecules. 18: 10973-10988.

Irshad, M., S. Yamamoto, A. E. Eneji, T. Endo, and T. Honna (2002). Urea and manure effect on growth and mineral contents of maize under saline conditions. Journal of Plant Nut. 25: 189200.

Karanlik, S. (2001). Resistance to salinity in different wheat genotypes and physiological mechanisms involved in salt resistance. Ph.D. Thesis. Graduate School of Natural and Applied Sciences, University of Cukurova, Adana, Turkey.

Koh, E., S. Charoenprasert, and A. E. Mitchell (2012). Effect of organic and conventional cropping systems on ascorbic acid, vitamin C, flavonoids, nitrate, and oxalate in 27 varieties of spinach (Spinacia oleracea L.). J. Agricultural and Food Chem. 60: 3144-3150.

Kusvuran, S., S. Ellialtioglu, and Z. Polat (2013). Antioxidative enzyme activity, lipid peroxidation, and proline accumulation in the callus tissues of salt and drought tolerant and sensitive pumpkin genotypes under chilling stress. Horticulture, Environment, and Biotechnology. 54: 319-325.

Kusvuran, S., E. Kaya, and S. Ellialtioglu (2018). The effect of organic fertilizer on salt tolerance in rocket. II. International Scientific and Vocational Studies Congress Proceeding Books, 593-598.

Jabeen, N. and R. Ahmad (2017). Growth response and nitrogen metabolism of sunflower (Helianthus annuus L.) to vermicompost and biogas slurry under salinity stress. J. Plant Nut. 40: 104-114. 
Leskovar, D. and Y. A. Othman (2018). Organic and conventional farming differentially influenced soil respiration, physiology, growth and head quality of artichoke cultivars. J. Soil Science and Plant Nut. 18: 865-880.

Macknight, R. C., W. A. Laing, S. M. Bulley, R. C. Broad, A. A. Johnson, and R. P. Hellens (2017). Increasing ascorbate levels in crops to enhance human nutrition and plant abiotic stress tolerance. Current Opinion in Biotech. 44: 153160.

Markou, G. and E. Nerantzis (2013). Microalgae for high-value compounds and biofuels production: a review with focus on cultivation under stress conditions. Biotechnology Advances 31: 15321542.

Medina-Juárez, L. Á., D. Molina-Quijada, C. L. Del Toro Sánchez, G. A. González-Aguilar, and N. Gámez-Meza (2012). Antioxidant activity of peppers (Capsicum annuum L.) extracts and characterization of their phenolic constituents. Interciencia. 37:588-593.

Miceli, A., A. Moncada, and F. D'Anna (2003). Effect of water salinity on seeds-germination of Ocimum basilicum L., Eruca sativa L. and Petroselinum hortense Hoffm. In International Symposium on Managing Greenhouse Crops in Saline Env. 609: 365-370.

Nardi, S., D. Pizzeghello, A. Muscolo, and A. Vianello (2002). Physiological effects of humic substances on higher plants. Soil Biology and Biochem.34: 1527-1536.

Nasiri, Y. (2016). Effect of plant growth regulators and organic manure on some morphological characters, biomass and essential oil yield of dragonhead (Dracocephalum moldavica). Botanica Lithuanica. 22: 123-132.

Ozdemir, A. E. and O. Dundar (2006). The effects of fungicide and hot water treatments on the internal quality parameters of Valencia oranges. Asian J Plant Sci. 5:142-146.

Pang, Q., J. Guo, S. Chen, Y. Chen, L. Zhang, M. Fei, S. Jin, M. Li, Y. Wang, and X. Yan (2012). Effect of salt treatment on the glucosinolatemyrosinase system in Thellungiella salsuginea. Plant and Soil. 355: 363-374.

Parihar, P., S. Singh, R. Singh, V. P. Singh, and S. M. Prasad (2015). Effect of salinity stress on plants and its tolerance strategies: A review. Environmental Science and Pollution Research. 22: 4056-4075.

Quin, P., S. Joseph, O. Husson, S. Donne, D. Mitchell, P. Munroe, and L. Van Zwieten (2015). Lowering
$\mathrm{N}_{2} \mathrm{O}$ emissions from soils using eucalypt biochar: the importance of redox reactions. Scientific Rep. 5:1-14.

Sairam, R. K., G. C. Srivastava, S. Agarwal, and R. C. Meena (2005). Differences in antioxidant activity in response to salinity stress in tolerant and susceptible wheat genotypes. Biologia Plantarum. 49: 85.

Sarıkamış, G. and A. Çakır (2017). Influence of salinity on aliphatic and indole glucosinolates in broccoli (Brassica oleracea var. Italica). Applied Ecological Environment Research. 15: 1781-1788.

Schröder, F. G. and J. H. Lieth (2002). Irrigation control in hydroponics. In: Savvas D, Passam H (eds) Hydroponic production of vegetables and ornamentals. Embryo, Athens, pp 263-298.

Sen, A. (2012). Oxidative stress studies in plant tissue culture. In: Antioxidant Enzyme, Amr ElMissiry, M (eds). IntechOpen, doi: $10.5772 / 48292$.

Shaaban, M., M. Abid, and R. A. I. Abou-Shanab (2013). Amelioration of salt affected soils in rice paddy system by application of organic and inorganic amendments. Plant, Soil and Envir. 59: 227-233.

Singh, R., A. K. Upadhyay, and D. P. Singh (2018). Regulation of oxidative stress and mineral nutrient status by selenium in arsenic treated crop plant Oryza sativa. Ecotoxicology and Environmental Safety 148: 105-113.

Singleton, V. L., R. Orthofer, and R. M. LamuelaRaventós (1999). Analysis of total phenols and other oxidation substrates and antioxidants by means of folin-ciocalteu reagent. Methods in Enzymology 299: 152-178.

Sutrisno, S. and E. Yusnawan (2018). Effect of Manure and Inorganic Fertilizers on Vegetative, Generative Characteristics, Nutrient, and Secondary Metabolite Contents of Mungbean. Biosaintifika: Journal of Biology \& Biology Education. 10 (1): 56-65.

Villatoro-Pulido, M., R. Font, S. Saha, S. Obregón-Cano, J. Anter, A. Munoz- Serrano, A. De HaroBailon, A. Alonso-Morago, and M. Del Rio Celestino (2012). In vivo biological activity of rocket extracts (Eruca vesicaria subsp. sativa (Miller) Thell) and sulforaphane. Food and Chemical Tox. 50: 1384-1392.

Yuan, G., X. Wang, R. Guo, and Q. Wang (2010). Effect of salt stress on phenolic compounds, glucosinolates, myrosinase and antioxidant activity in radish sprouts. Food Chem. 121: 1014-1019. 